Check for updates

Cite this: RSC Adv., 2019, 9, 8935

\title{
The graviola impact on human astroglioma cells: functional significance of MUDENG
}

\author{
Judy Gopal, (D) $\dagger^{\mathrm{b}}$ Yoon-Mi Lee, $\uparrow^{\mathrm{a}}$ Juhyun Shin, ${ }^{\mathrm{a}}$ Manikandan Muthu, ${ }^{\mathrm{b}}$ \\ Seunghwa Jung, ${ }^{a}$ Somi Jeong, ${ }^{a}$ Jeongheon $\mathrm{Oh}^{\mathrm{a}}$ and Jae-Wook Oh*a
}

Graviola (Annona muricate) is a coveted tropical plant that has been found to be effective against many human cancers. Malignant glioblastoma multiformes are the most common and aggressive malignant forms of astrocytoma in the central nervous system. MUDENG (Mu-2-related death-inducing gene, $\mathrm{MuD}$ ) is involved in cell death signaling. In this study, we investigated the impact of extracts from graviola leaves (from Korea and Africa), fruits and seeds against human astroglioma cells. Interestingly, graviola leaf extract-Korea (GLE-K), graviola leaf extract-Africa (GLE-A) and graviola fruit extract-Africa (GFE-A) exhibited significant cytotoxic effects on the cell proliferation in a dose-dependent manner and altered the MuD expression pattern. Cell cycle analyses revealed that GLE-A and GLE-K triggered no significant induction of apoptosis at concentrations up to $5 \%$ in U251-MG cells, while in GLE-K treated cells at $10 \%$ concentrations, there were much fewer apoptotic cells (33.64\%) compared to those in GLE-A (73.55\%) treated cells. In the case of GFE-A treated cells, 5\% graviola extract (GE) concentration resulted in predominant cells entering the apoptotic phase (59.31\%), whereas almost no significant increase in apoptotic cells was observed in GSE-A treated cells $(1.38 \%$ ) even up to $25 \%$ of graviola extract (GE) concentration. While using stable transfectants knock-out $(K O)(-)$-and overexpressing $(\mathrm{OE})-\mathrm{MuD}(+)$, significant and consistent differences in the cell viability (enhanced anti-astroglioma effect of GEs) were observed in $\mathrm{KO}-\mathrm{MuD}(-)$ cells. This validated the functional consequence of $\mathrm{MuD}$ in the anti-astroglioma activity of GEs. Our results confirmed that GFE-A possesses the highest anti-astroglioma activity followed by the leaf extracts $(G L E-A / K)$. This is the first report that highlights the MuD aspect of GEs.

Received 6th December 2018

Accepted 24th February 2019

DOI: $10.1039 / \mathrm{c} 8 \mathrm{ra10039j}$

rsc.li/rsc-advances

\section{Introduction}

Astrocytes, also known collectively as astroglia, are the most abundant cell types in the brain and have important physiological properties as they contribute to homeostasis in the central nervous system (CNS). They affect neuronal function by releasing neurotrophic factors, guiding neuronal development, and contributing to the metabolism of neurotransmitters. ${ }^{1}$ Astrocytes influence the formation and maintenance of the blood-brain barrier, a structure that serves to limit the entry of blood-borne components into the CNS. Malignant glioblastoma multiformes are heterogeneous high-grade gliomas containing multiple genetically aberrant clones. It is the most common and aggressive malignant form of astrocytoma in the CNS. ${ }^{2}$ The median survival of patients with glioblastomas is only 12-15 months, post diagnosis.

MUDENG (Mu-2-related death-inducing gene, $M u D)$ is a novel gene discovered while screening for genes associated with Fas-mediated

${ }^{a}$ Department of Stem Cell and Regenerative Biotechnology, Department of Animal Biotechnology, Konkuk University, 120 Neungdong-ro, Gwangjin-gu, Seoul 05029, Korea. E-mail: ohjw@konkuk.ac.kr; Fax: +82-2-455-1044; Tel: +82-2-2049-6271

${ }^{b}$ Department of Environmental Health Sciences, Konkuk University, Seoul 05029, Korea

$\dagger$ These authors contributed equally to this work. apoptosis. $^{3} \mathrm{MuD}$ protein contains a $\mathrm{Mu}(\mu)$ homology domain found in adaptor proteins that play important roles in intracellular trafficking pathways and is known to be involved in the initial stages of cell death in cytotoxic T cells. ${ }^{4}$ Furthermore, we have reported that MuD possesses anti-apoptotic functions ${ }^{5}$ and is involved in silver nanoparticle (AgNP)-induced astroglioma hormesis. ${ }^{6}$

Graviola (Annona muricate) is commonly called as soursop or Brazilian paw paw and belongs to the Annonaceae family, scientifically known as Annona muricate. ${ }^{7}$ The bark, leaves, roots, fruits, and seeds have their own unique uses and specific properties. ${ }^{7,8}$ Ethnomedicinal practices in Africa and South America exploit this plant's extracts in their conventional and alternative medicine. The anti-convulsant, anti-parasitic, antiarthritic, anti-malarial, anti-diabetic, hepatoprotective and anti-cancer properties of this plant are well established. ${ }^{79}$ Bio- $^{7}$ logical and biochemical characterization of the extracts indicate that annonaceous acetogenins are the main ingredients of graviola. ${ }^{10,11}$ Principally, graviola plays a predominant role in promoting anticancer activity. Graviola leaves have been subjected to investigation against human diseases, of which cancer is the most reported..$^{12}$ In the United States and Europe, graviola is sold as a popular adjunctive natural therapy for cancer. The key biomolecules responsible for the bioactive properties of 
graviola are the acetogenins. These acetogenins have demonstrated to be highly versatile and display selective toxicity to tumor cells at even trace dosages (1 part per million). Acetogenins in graviola further demonstrated their strong anticancerous, anti-tumor and anti-viral properties. ${ }^{7,9,13}$

This study validates the impact of extracts from graviola leaves (from Korea and Africa), fruits and seeds against human astroglioma cells. The anti-cancer effects of various plant parts of graviola and within the same plant part (leaf) obtained from geographically different sources have been compared for their variations in anti-cancer activity. We present for the first time the correlation between graviola anti-cancer activity and MuD. This study reveals the underlying mechanism for the anticancer activity of graviola extracts from a MuD perspective.

\section{Materials and methods}

\section{Preparation and characterization of graviola extracts (GEs)}

Dried graviola leaves were procured from Gyeongdong market (a big traditional market in Seoul, Korea), and dried leaves, fruits and seeds were obtained from Uganda, Africa. Four grams of the respective sample was used for the extraction procedure. A coboiling water extraction methodology was practiced, since our previous experiments ${ }^{\mathbf{1 4}}$ had confirmed that the co-boiling method was more efficient. Previous authors mostly employed a methodology where the leaves were introduced into boiling water, while in our extraction methodology, leaves were added to water and boiled together (co-boiled). The leaves were added to $200 \mathrm{~mL}$ sterile water in a flask and the contents were boiled until they were evaporated to half the original volume. The evaporation procedure was performed to concentrate the bioactive components in the extracts. The leaves were added to $200 \mathrm{~mL}$ sterile water in a flask and the contents boiled until evaporated to half the original volume. The extracts of the graviola leaves from Korea was coded as GLE-K (graviola leaf extract-Korea), and that from Africa (A) was coded as GLE-A. Codes GFE-A and GSE-A referred to graviola fruit and graviola seed extracts from Africa. These codes will be used in the subsequent sections. The extracts were characterized using a Nanodrop ND-1000 v3.3.1 spectrophotometer (Nanodrop Technologies, Wilmington, USA) by scanning in the range of 200-700 nm, and using Fouriertransform infrared spectroscopy (FTIR) (Shimadzu FTIR-8300 spectrometer, San Diego, CA, USA).

\section{Cell viability assay}

For this study, human malignant glioblastoma multiforme U251-MG and T98G cells were used. U251-MG was obtained from Dr Benveniste EN (University of Alabama at Birmingham, Birmingham, AL, USA). T98G cells were obtained from Dr Lee J. H. (Department of Biochemistry, College of Medicine, The Catholic University of Korea, Seoul, Korea). Both cell types $(5 \times$ $10^{4}$ cells per well), grown in 24 -well plates overnight, were treated for $24 \mathrm{~h}$ with the indicated percentage concentrations $(0-50 \%)$ of the four different graviola extracts (GLE-K, GLE-A, GFE-A, and GSE-A). Wild type (wt) U251-MG, U251-MuD knock-out (KO), and U251-MuD over-expressing (OE) cells $(1 \times$
$10^{5}$ cells per well), cultured in 24 -well plates overnight, were treated for $12 \mathrm{~h}$ with the indicated percentage concentrations $(0-50 \%)$ of each GE. Cell viability was measured in 24-well plates using a colorimetric assay with 2-(4-iodophenyl)-3-(4nitrophenyl)-5-(2,4-disulfophenyl)- $2 H$-tetrazolium monosodium salt (WST-1) reagent. The absorbance was determined at $450 \mathrm{~nm}$ using a microplate reader (Bio-Tek, Winooski, VT, USA). The absorbance was directly proportional to the number of viable cells since the tetrazolium salts in WST-1 cleave into formazan by mitochondrial dehydrogenases in the cells. All experiments were performed in triplicate and the relative cell viability (\%) was expressed (in percentage) relative to the untreated control cells.

\section{Immunoblot analysis}

Grown cells were lysed in lysis buffer (1\% NP-40, 0.5\% sodium deoxycholate, $0.1 \%$ SDS, $50 \mathrm{mM}$ Tris-Cl, $0.02 \%$ sodium azide, and $150 \mathrm{mM} \mathrm{NaCl}$; supplemented with $1 \mathrm{mM}$ phenylmethylsulfonylfluoride, $2 \mu \mathrm{g} \mathrm{mL}^{-1}$ aprotinin, $1 \mu \mathrm{g} \mathrm{mL}^{-1}$ leupeptin, $1 \mu \mathrm{g} \mathrm{mL}^{-1}$ pepstatin A, $2 \mathrm{mM}$ sodium fluoride, and $1 \mathrm{mM}$ sodium orthovanadate). Cell lysates $(30 \mu \mathrm{g})$ were subjected to sodium dodecyl sulphate-polyacrylamide gel electrophoresis (SDS-PAGE) and transferred onto a polyvinyl difluoride membrane, which was then blocked with $5 \%$ non-fat milk. The membrane was incubated with the prepared antibodies overnight at $4{ }^{\circ} \mathrm{C}$ followed by incubation with HRP-conjugated secondary antibodies at room temperature for $2 \mathrm{~h}$. The bands were detected via enhanced chemiluminescence (Bio-Rad, Hercules, CA, USA).

\section{Flow cytometric analysis}

Flow cytometry (ACEA Biosciences, San Diego, CA, USA) was used to characterize the effect of GEs on cell cycle distribution. Cells incubated with GEs for $24 \mathrm{~h}$ were collected and centrifuged at $1500 \mathrm{rpm}$ for 5 minutes. The harvested cells were fixed with pre-cooled $70 \%$ ethanol at $-20{ }^{\circ} \mathrm{C}$ for 15 minutes. Cells were then subjected to propidium iodide (PI) staining for 15 minutes in the dark. Apoptotic cells with hypodiploid DNA content were measured using NovoExpress software (ACEA Biosciences).

\section{Statistical analysis}

Data are presented as the mean \pm standard deviation from triplicates of independent experiments. Statistical analysis was performed using IBM SPSS for Windows version 12.0 (SPSS Inc., Chicago, IL, USA). A one-way analysis of variance (ANOVA) was used to determine the statistical significance of multiple comparisons by Duncan's multiple range test. A $p$-value lower than $0.05,0.01$, and 0.001 , respectively, was considered statistically significant.

\section{Results and discussion}

\section{Anti-astroglioma activity of GEs}

The cytotoxicity of the four different extracts on U251-MG and T98G astroglioma cells was evaluated. GLE-K and GLE-A, both 
extracts from graviola leaves but from geographically different locations, were assessed for their effects on the astroglioma cells. In terms of cytotoxic activity, very subtle variation with negligible significance was observed between the cells treated with GLE-K and GLE-A. These results show that differences in geographical distribution did not have any profound impact on graviola's anti-astroglioma properties. However, a significant anti-astroglioma activity was evident for the GLE-K, GLE-A and GFE-A extracts. These results show that differences in geographical distribution did not have any profound impact on graviola's anti-astroglioma properties. Yet, significant antiastroglioma activity was evident from the GLE-K, GLE-A and GFE-A extracts. As observed from Fig. 1, extract concentrations ranging from 0 to $1,5,10,25$, and $50 \%$ were examined. In terms of cytotoxic activity very subtle and marginal variation, that which we can say of negligible significance was observed between GLE-K and GLE-A. However, significant antiastroglioma activity was evident for GLE-K, GLE-A and GFE-A extracts. As usually reported, the effect was more pronounced for U251-MG (Fig. 1A) than for the usually more resistant T98G cells (Fig. 1B). Recently, Ryu et al. reported that T98G cells were more resistant to TMZ and Valproic acid than U251-MG cells. ${ }^{15}$ These differences show that even the same human malignant glioblastomas could show profoundly varied responses to drugs. Consolidating the comparative study of the different plant parts of graviola, it was confirmed that the fruit (GFE-A) presented the highest activity, which was followed by the leaf extracts (GLE-A and GLE-K) and the lowest activity or almost insignificant activity was presented by the seed extracts (GSE-A). Interestingly, GLE-K and GFE-A (at 25\% extract concentrations) were also successful against the more resistant T98G cells.

\section{GE-MuD impact assessment}

The fact that the viability and the expression level of the MuD protein decreases following tumor necrosis factor-related apoptosis-inducing ligand (TRAIL) treatment was already reported. ${ }^{5}$ Furthermore, since MuD was identified during a screening for genes associated with death-receptor-mediated apoptosis, ${ }^{3}$ it was affirmed that MuD exhibited an antiapoptotic function following TRAIL treatment in astroglioma cells. Choi et al. ${ }^{5}$ have correlated that MuD had an important role in TRAIL-mediated apoptotic signaling.

The impact of the extracts on MuD expression was evaluated on U251-MG and T98G cells; Fig. 2A and B give the results of this assessment. As observed from the figures, MuD expression was altered upon the exposure of astroglioma cells to different concentrations of GEs. Although, no systematic trend was evident with various concentrations of extracts, significant correlations between the four different extracts on MuD expression were observed. GLE-A presented the highest antagonistic activity against MuD expression, followed by GFE-A and GLE-K.

The effect of GEs on the various phases in the cell cycle of astroglioma cells was also studied. The effects of GLE-A, GLE-K, GFE-A and GSE-A on G1, S, G2/M phases of cell cycles, and the percentage (\%) of cell population undergoing apoptosis are presented in Fig. 3. With respect to U251-MG cells, GLE-A and GLE-K treated cells showed no significant induction of apoptosis at concentrations up to 5\% (Fig. 3A-a and A-b), while for GLE-K treated cells at $10 \%$ concentration, apoptotic cells were much lesser (33.64\%, Fig. 3A-b) when compared with those for GLE-A treated cells $(73.55 \%$, Fig. 3A-a). In the case of GFE-A, $5 \%$ GE concentration resulted in predominant cells entering the apoptotic phase $(53.59 \%$, Fig. 3A-c), whereas almost no significant increase in apoptotic cells was observed in GSE-A treated cells even up to $25 \%$ of GE concentration (1.38\%, Fig. 3A-d). Fig. 3B presents the results for T98G cells, which clearly portray that T98G cells are much more resistant than U251-MG cells. Even concentrations up to $50 \%$ in the case of GLE-A, GLE-K and GSE-A did not result in significant apoptosis. Interestingly, 25-50\% concentrations of GFEA resulted in the induction of apoptosis even in the T98G cells.
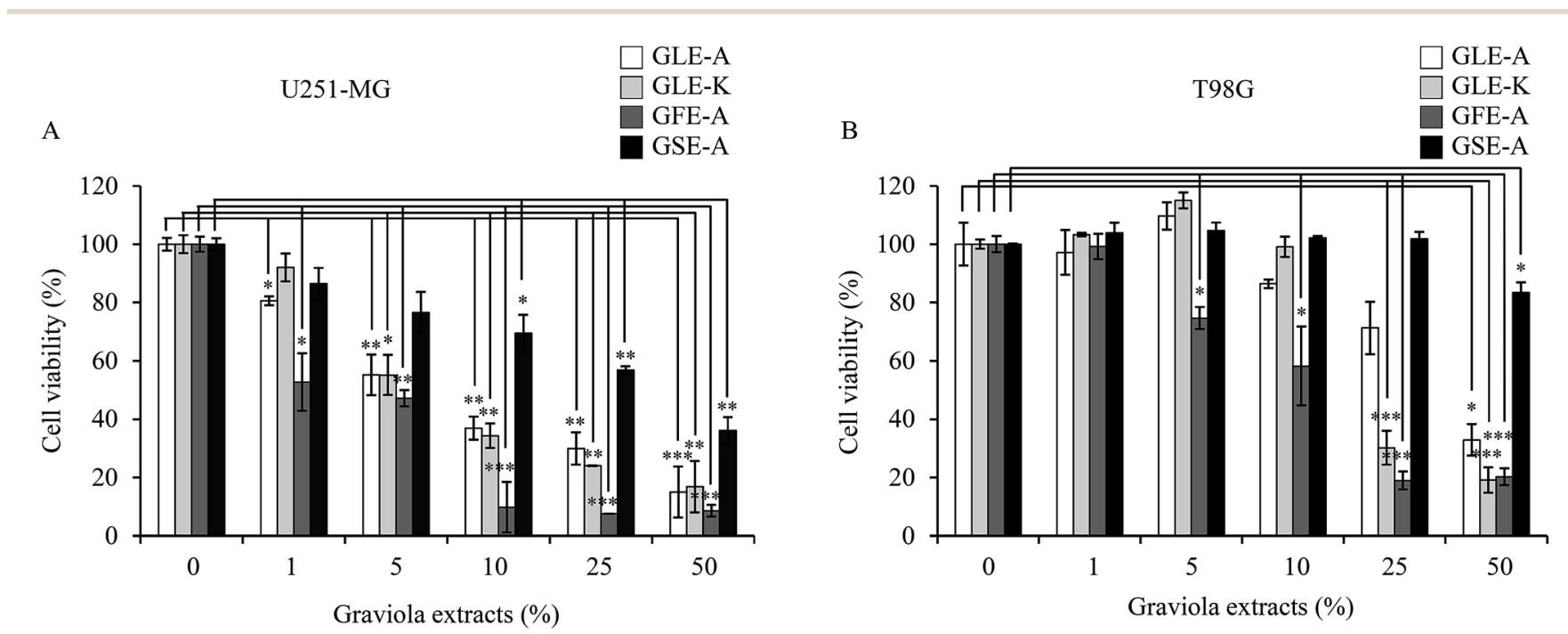

Fig. 1 Effects of GEs on U251-MG and T98G cell viability. Cells were incubated for $24 \mathrm{~h}$ with various concentrations of GEs (GLE-A/GLE-K/GFEA/GSE-A, 0-50\%). After $24 \mathrm{~h}$ treatment, cell viability was determined using a WST-1 assay. The cell viabilities at the mass concentrations are shown in (A, U251-MG) and (B, T98G), respectively. The results presented are the mean \pm SD of three experiments (significant versus control, * $p<$ $0.05, * * p<0.01, * * * p<0.001)$. 
A

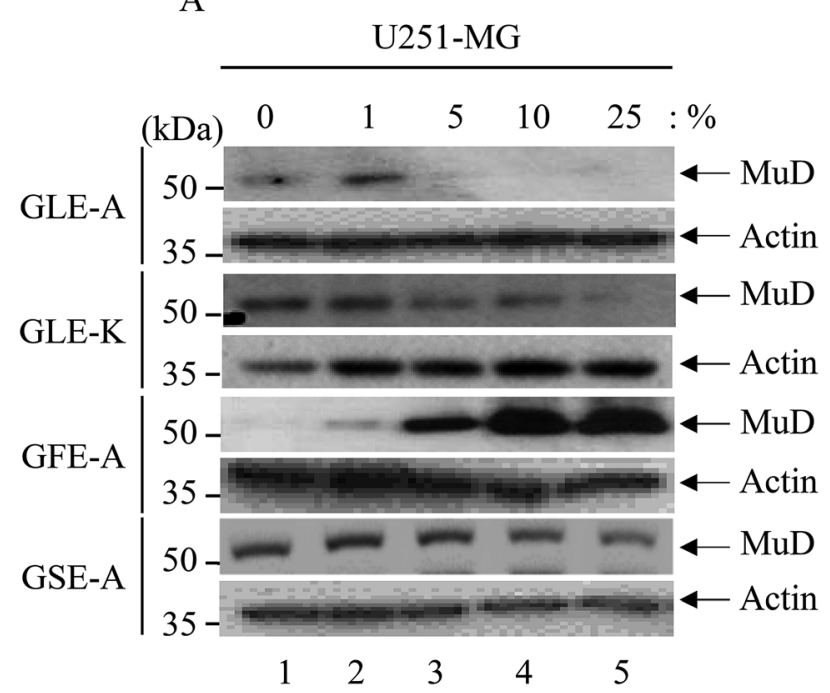

B

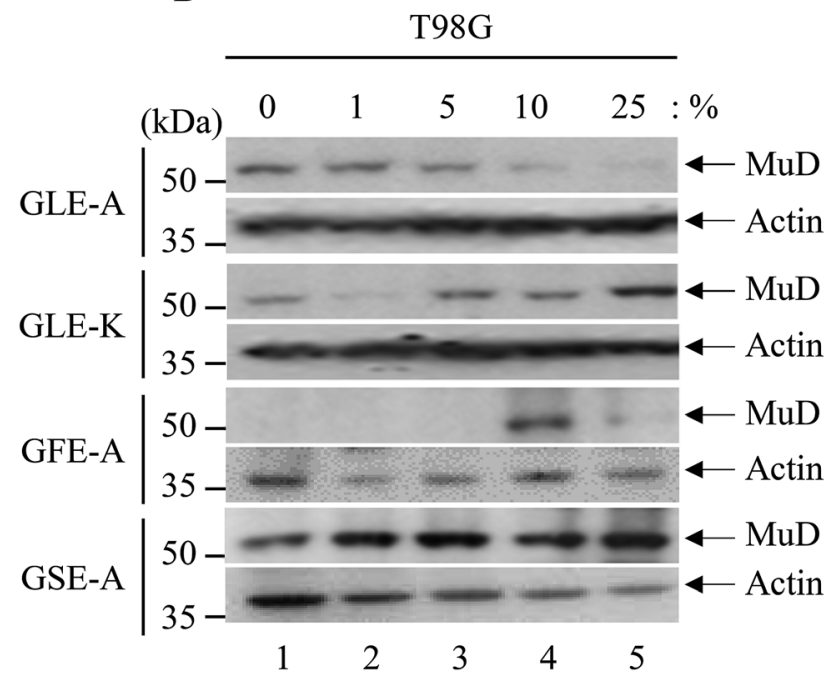

Fig. 2 MuD expression upon GEs stimulation. U251-MG and T98G cells $\left(3 \times 10^{5}\right.$ cells per well) grown in 6 -well plates were treated with various concentrations of GEs $(0-25 \%)$ for $12 \mathrm{~h}$. Cell lysates were separated by $10 \%$ SDS-PAGE, then transferred onto a PVDF membrane. The pattern of MuD protein expression was analyzed using anti-MuD MAb; $\beta$-actin served as a loading control. Results shown are representative of three experiments.

Apoptosis, or programmed cell death, is integral for normal development and tissue homeostasis in most multicellular organisms. ${ }^{16}$ Apoptosis plays a vital role in destroying cells that are selectively unnecessary or present a threat to the integrity of an organism, thereby limiting the development and/or spread of cancer. ${ }^{17}$ In many cancers, however, the gene(s) regulating apoptosis are faulty, which leads to uncontrolled proliferation. ${ }^{.6}$ The ability to induce cellular apoptosis in tumor tissues is the

\begin{tabular}{lrrrrrr}
\multicolumn{7}{c}{ A. U251-MG } \\
\hline a. GLE-A (\%) & \multicolumn{1}{c}{0} & \multicolumn{1}{c}{1} & \multicolumn{1}{c}{5} & \multicolumn{1}{c}{10} & \multicolumn{1}{c}{25} & \multicolumn{1}{c}{50} \\
\hline \hline Apoptosis (\%) & 0.92 & 1.44 & 3.07 & 73.55 & 73.95 & 76.85 \\
$\mathrm{G}_{1}(\%)$ & 67.97 & 72.10 & 77.63 & 25.10 & 22.10 & 21.47 \\
$\mathrm{~S}(\%)$ & 9.91 & 9.24 & 8.14 & 1.20 & 3.39 & 1.31 \\
$\mathrm{G}_{2} \mathrm{M}(\%)$ & 21.83 & 17.22 & 11.16 & 0.15 & 0.65 & 0.37 \\
\hline
\end{tabular}

\begin{tabular}{lrrrrrr}
\hline b. GLE-K (\%) & \multicolumn{1}{c}{0} & \multicolumn{1}{c}{1} & \multicolumn{1}{c}{5} & \multicolumn{1}{c}{10} & \multicolumn{1}{c}{25} & \multicolumn{1}{c}{50} \\
\hline \hline Apoptosis (\%) & 0.93 & 0.78 & 1.74 & 33.64 & 30.03 & 40.36 \\
$\mathrm{G}_{1}(\%)$ & 65.93 & 77.49 & 74.17 & 50.79 & 53.66 & 49.41 \\
$\mathrm{~S}(\%)$ & 14.40 & 7.16 & 8.79 & 7.80 & 7.50 & 4.47 \\
$\mathrm{G}_{2} \mathrm{M}(\%)$ & 18.74 & 14.57 & 15.30 & 7.77 & 8.81 & 5.76 \\
\hline
\end{tabular}

\begin{tabular}{lrrrrrr}
\hline c. GFE-A (\%) & \multicolumn{1}{c}{0} & \multicolumn{1}{c}{1} & \multicolumn{1}{c}{5} & \multicolumn{1}{c}{10} & \multicolumn{1}{c}{25} & \multicolumn{1}{c}{50} \\
\hline \hline Apoptosis (\%) & 0.51 & 16.81 & 53.59 & 59.31 & 73.30 & 80.15 \\
$\mathrm{G}_{1}(\%)$ & 77.01 & 59.77 & 36.39 & 34.90 & 18.60 & 18.33 \\
$\mathrm{~S}(\%)$ & 12.27 & 14.95 & 4.08 & 3.80 & 3.94 & 1.01 \\
$\mathrm{G}_{2} \mathrm{M}(\%)$ & 10.21 & 8.47 & 5.94 & 1.99 & 4.16 & 0.51 \\
\hline
\end{tabular}

\begin{tabular}{lrrrrrr}
\hline d. GSE-A (\%) & \multicolumn{1}{c}{0} & \multicolumn{1}{c}{1} & \multicolumn{1}{c}{5} & \multicolumn{1}{c}{10} & \multicolumn{1}{c}{25} & \multicolumn{1}{c}{50} \\
\hline \hline Apoptosis (\%) & 1.577 & 1.93 & 1.38 & 0.23 & 0.560 & 6.81 \\
$\mathrm{G}_{1}(\%)$ & 79.98 & 81.11 & 81.01 & 84.44 & 83.37 & 43.89 \\
$\mathrm{~S}(\%)$ & 5.19 & 7.29 & 6.18 & 7.40 & 6.81 & 21.98 \\
$\mathrm{G}_{2} \mathrm{M}(\%)$ & 13.26 & 9.78 & 11.43 & 7.93 & 9.26 & 27.32 \\
\hline
\end{tabular}

\begin{tabular}{|c|c|c|c|c|c|c|}
\hline \multicolumn{7}{|c|}{ B. $\mathrm{T} 98 \mathrm{G}$} \\
\hline GLE-A $(\%)$ & 0 & 1 & 5 & 10 & 25 & 50 \\
\hline Apoptosis (\%) & 0.69 & 4.50 & 7.46 & 7.45 & 11.66 & 15.59 \\
\hline $\mathrm{G}_{1}(\%)$ & 77.08 & 74.95 & 65.01 & 61.84 & 77.35 & 80.44 \\
\hline $\mathrm{S}(\%)$ & 11.16 & 8.46 & 7.58 & 7.14 & 5.02 & 2.05 \\
\hline $\mathrm{G}_{2} \mathrm{M}(\%)$ & 11.07 & 12.09 & 19.95 & 23.57 & 5.97 & 1.92 \\
\hline GLE-K (\%) & 0 & 1 & 5 & 10 & 25 & 50 \\
\hline Apoptosis (\%) & 0.54 & 1.30 & 0.26 & 1.84 & 14.25 & 20.87 \\
\hline $\mathrm{G}_{1}(\%)$ & 78.94 & 76.18 & 77.32 & 76.79 & 61.34 & 42.66 \\
\hline $\mathrm{S}(\%)$ & 9.46 & 9.60 & 9.15 & 10.15 & 7.38 & 12.18 \\
\hline $\mathrm{G}_{2} \mathrm{M}(\%)$ & 11.06 & 12.92 & 13.27 & 11.22 & 17.03 & 24.29 \\
\hline GFE-A (\%) & 0 & 1 & 5 & 10 & 25 & 50 \\
\hline Apoptosis (\%) & 0.68 & 3.22 & 22.42 & 26.13 & 55.28 & 69.84 \\
\hline $\mathrm{G}_{1}(\%)$ & 78.41 & 71.29 & 58.08 & 56.04 & 34.59 & 28.75 \\
\hline S (\%) & 10.15 & 13.57 & 10.87 & 9.32 & 4.59 & 1.36 \\
\hline $\mathrm{G}_{2} \mathrm{M}(\%)$ & 10.76 & 11.92 & 8.63 & 8.51 & 5.54 & 0.05 \\
\hline GSE-A (\%) & 0 & 1 & 5 & 10 & 25 & 50 \\
\hline Apoptosis (\%) & 1.62 & 1.33 & 1.08 & 1.99 & 1.66 & 3.75 \\
\hline $\mathrm{G}_{1}(\%)$ & 67.81 & 65.97 & 61.77 & 70.39 & 68.12 & 58.03 \\
\hline S (\%) & 18.88 & 21.85 & 25.37 & 19.18 & 20.08 & 25.32 \\
\hline $\mathrm{G}_{2} \mathrm{M}(\%)$ & 11.69 & 10.85 & 11.78 & 8.44 & 10.14 & 12.90 \\
\hline
\end{tabular}

Fig. 3 Cell cycle analyses after GEs stimulation. U251-MG (A) and T98G cells (B) $\left(3 \times 10^{5}\right.$ cells) was incubated in $1.5 \mathrm{~mL}$ serum free media with GEs $(0-50 \%)$ at $37^{\circ} \mathrm{C}$ in a 6 -well plate. After incubation for $48 \mathrm{~h}$, cells were suspended in $1 \mathrm{~mL}$ of PBS by pipetting after washing once with icecold PBS. Full volume of re-suspended cells was added dropwise into $4 \mathrm{~mL}$ of cold absolute ethanol and then incubated for 15 min at $-20{ }^{\circ} \mathrm{C}$. Ethanol was discarded and the cells were pelleted and re-suspended in $1 \mathrm{~mL}$ of $20 \mu \mathrm{M}$ PI solution (catalog no. P21493) (Thermo Fisher Scientific, Lafayette, CO, USA). After 15 min incubation at RT, FACs analysis was performed using a NovoCyte flow cytometer (ACEA Biosciences, San Diego, CA, USA). Data was analyzed using a NovoExpress software (ACEA Biosciences). Data presented is representative of three experiments. 
key to finding a successful natural product as an anti-cancer agent. ${ }^{18,19}$

In order to discern the positive correlation of MuD expression in the anti-astroglioma activity of GEs, stable transfectants knock-out (KO)(-)-and overexpressing (OE)-MuD(+) were generated; the transfectants for further experiments were selected based on the presence and absence of MuD protein expression as determined by western blot analysis (Fig. 4A). Cell viability of the stable transfectants upon GEs stimulation was analyzed by WST- 1 assay. KO-MuD(-) and OE-MuD(+) cells were exposed to GLE-A, GLE-K, GFE-A and GSE-A extracts. Fig. 4B-E presents the results of this evaluation. As clearly observed, significant and consistent differences in cell viability (an enhanced anti-astroglioma effect of GEs) were observed in KO$M u D(-)$ cells, suggesting the functional consequence of $\mathrm{MuD}$ in the anti-astroglioma activity of GEs. The results of our study confirmed that graviola fruit extracts (GFE-A) possess the highest anti-astroglioma activity, followed by leaf extracts (GLE$\mathrm{A}>\mathrm{K}$ ). Ioannis et al. ${ }^{17}$ in their recent review, have also placed fruit extracts as the ones with higher anti-cancer activity followed by leaf extracts.

Graviola-derived compounds have been well correlated with a variety of anti-cancer effects that include cytotoxicity, ${ }^{20,21}$ induction of apoptosis, ${ }^{22}$ necrosis, ${ }^{23}$ and inhibition of proliferation $^{24,25}$ on a variety of cancer cell lines, including breast, ${ }^{26}$ prostate, ${ }^{25}$ colorectal, ${ }^{24}$ lung, ${ }^{21}$ leukemia, ${ }^{27}$ renal, ${ }^{28}$ pancreatic, ${ }^{20}$ hepatic, ${ }^{29}$ oral, ${ }^{30}$ melanoma, ${ }^{31}$ cervical, ${ }^{32}$ and ovarian cancers. ${ }^{33,34}$

The major bioactive components that have been extracted from various graviola parts are known as annonaceous acetogenins. These are derivatives of long-chain (C32 or C34) fatty acids derived from the polyketide pathway. ${ }^{35}$ These derivatives are said to display selective toxicity to cancer cells, and are successful even in multidrug-resistant cancer cell lines. ${ }^{7}$ Annonaceous acetogenins are reported to induce cytotoxicity, primarily by inhibiting mitochondrial complex I, which is involved in oxidative phosphorylation and ATP synthesis. ${ }^{36}$ As cancer cells have a higher demand for ATP than the normal cells, mitochondrial complex I inhibitors have huge potential for selective and targeted cancer therapy. ${ }^{37}$

For a long time GEs were used as indigenous home remedies; it is in the recent years that the scientific validation of this medicinal plant has become widespread. However, so far there has been no direct correlation of the anti-cancer activity of GEs with respect to MuD. This is the first report that is expected to streamline a new direction in the anti-cancer mechanism of these extracts.

The four different GEs used in this study were characterized using UV-Vis spectrophotometry and FTIR to ascertain the variations in their activities toward their bioactive acetogenin contents. Fig. 5A gives the UV-Vis scan from $220 \mathrm{~nm}$ to $600 \mathrm{~nm}$ and shows broad peaks, wherein the highest peak intensities of GFE-A and GLE-A followed by GLE-K were observed in the 220$230 \mathrm{~nm}$ range. Moreover, the GSE-A extract that showed least anti-astroglioma activity and negative correlation with MuD, showed a significantly reduced shoulder in this region. UV-Vis absorbances at wavelengths of $210 \mathrm{~nm}, 213 \mathrm{~nm}$, and 216$234 \mathrm{~nm}$ correlate with acetogenins..$^{38}$ According to the previous study, ${ }^{39}$ the absorption in the range of $220-230 \mathrm{~nm}$ is associated with the amine conjugated $\pi \rightarrow \pi^{*}$ transition. Ketolactone aromatic $\mathrm{C}-\mathrm{H}$ appear in the wavelength ranging from 216 to $234 \mathrm{~nm} .{ }^{40}$ Absorption at the wavelength of $230 \mathrm{~nm}$ indicates the presence of tetrahydrofuran group. According to Alali et al., ${ }^{40}$ the UV-Vis test results in a high absorbance at wavelengths
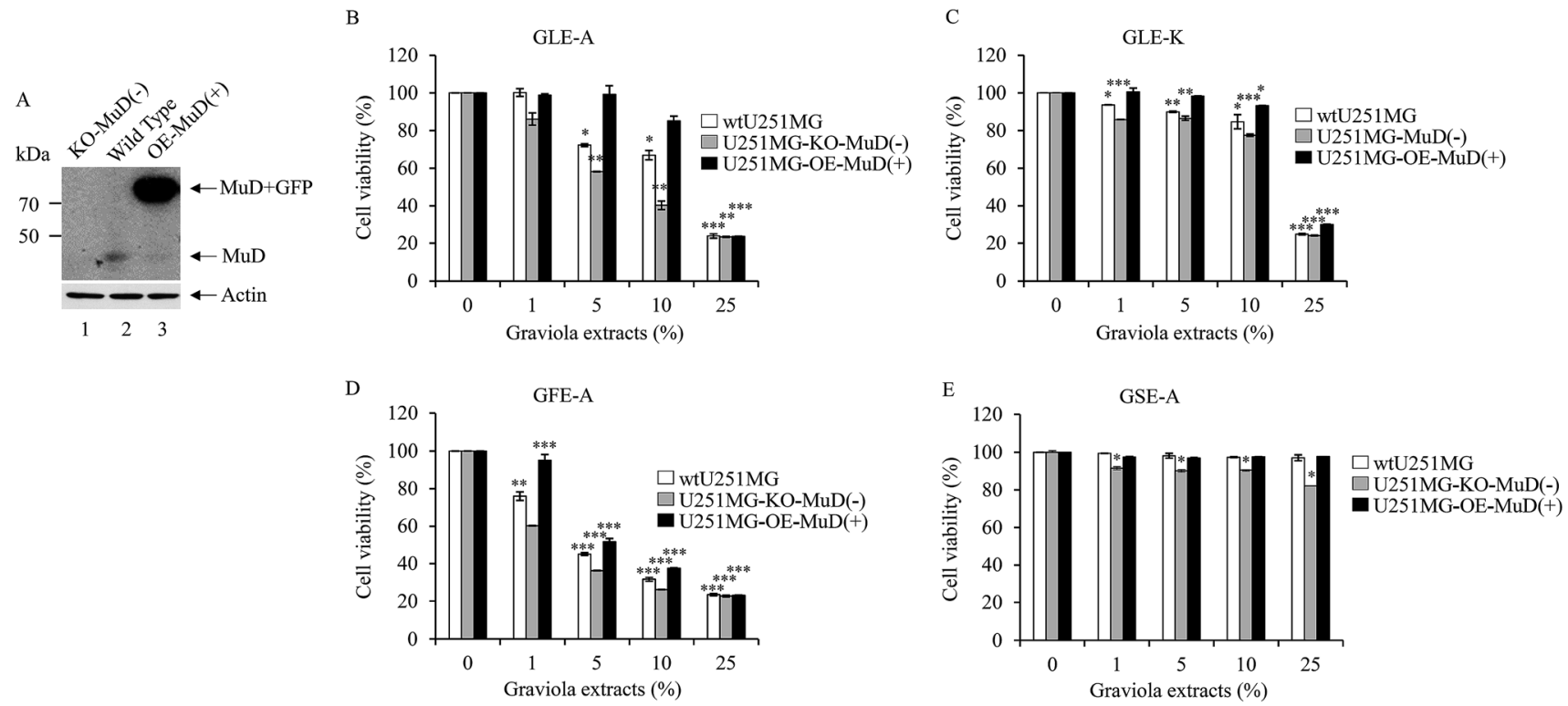

Fig. 4 MuD affects cell viability during exposure to GEs. wtU251-MG, U251-MG-MuD(-), and U251-MG-OE-MuD(+) cells were seeded at a density of $3 \times 10^{5}$ cells in 6 -well plates, respectively. Twelve hours after seeding, cells were treated with each GE (0-25\%) for $24 \mathrm{~h}$. Cell viability was measured using WST-1 reagent. Data presented are the mean \pm SD of three experiments (significant versus control, $* p<0.05, * * p<0.01$, $* * * p<0.001)$. The cells used in (B-E) experiments were lysed, subjected to $10 \%$ SDS-PAGE, and the amount of MuD was analyzed by western blot using anti-MuD MAb (A, up). The blot was re-probed with anti $\beta$-actin ( $A$, down). 


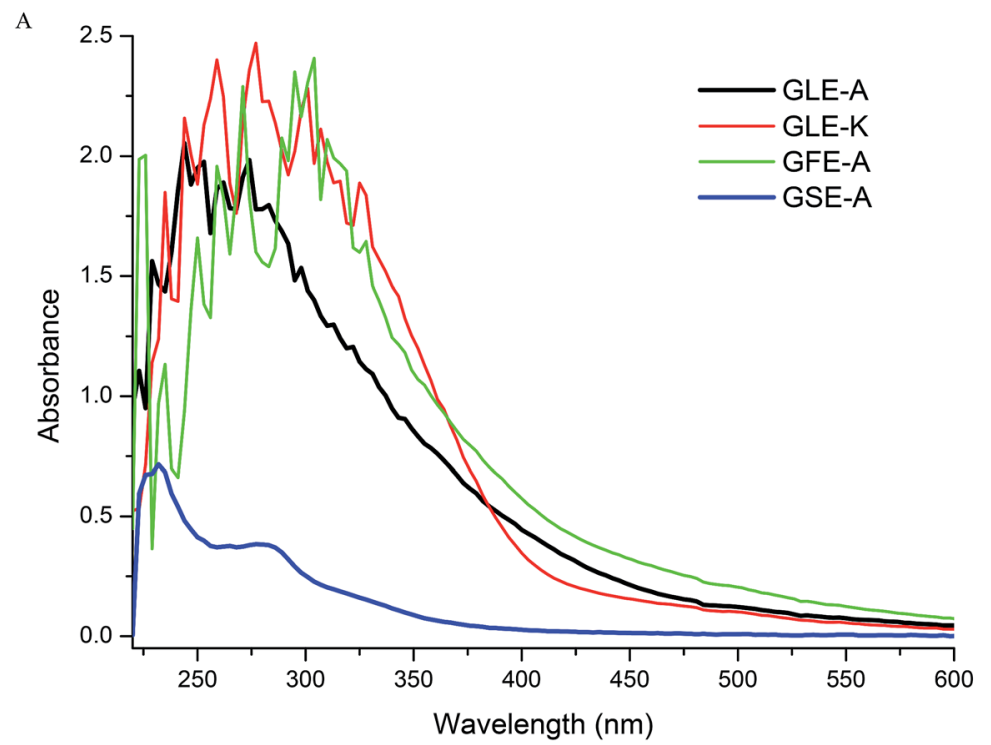

B

Fig. 5 UV-Vis results (A) showing variations in the absorption peaks of acetogenins from 210 to $230 \mathrm{~nm}$ among the four GEs. (B) UV absorption at $210 \mathrm{~nm}$ characteristic for acetogenins compared among the four GEs.

between 222 and $230 \mathrm{~nm}$, marking the presence of cluster ketolactone and tetrahydrofurans. Further, the absorbance at $210 \mathrm{~nm}$, which is expected to more precisely indicate acetogenins, ${ }^{38}$ was recorded for the four extracts. As observed from Fig. $5 \mathrm{~B}$, the acetogenin levels followed the same order in terms of absorbance intensity as their anti-astroglioma activity, i.e., GFE-A > GLE-A > GLE-K > GSE-A.

FTIR studies were also conducted to further validate the bioactive compounds present in the extracts. Acetogenin compounds have a characteristic form of the lactone group at one end that could be revealed using infrared spectroscopy. ${ }^{41} \mathrm{To}$ detect the presence of acetogenin, the absorption of infrared radiation in the range of $4.000-400 \mathrm{~cm}^{-1}$ was scanned. The results of the FTIR spectroscopy are shown in Fig. 6. The absorption at $3397.76 \mathrm{~cm}^{-1}$ indicates the presence of $\mathrm{O}-\mathrm{H}$ group, the absorption band at $2928.07 \mathrm{~cm}^{-1}$ denotes

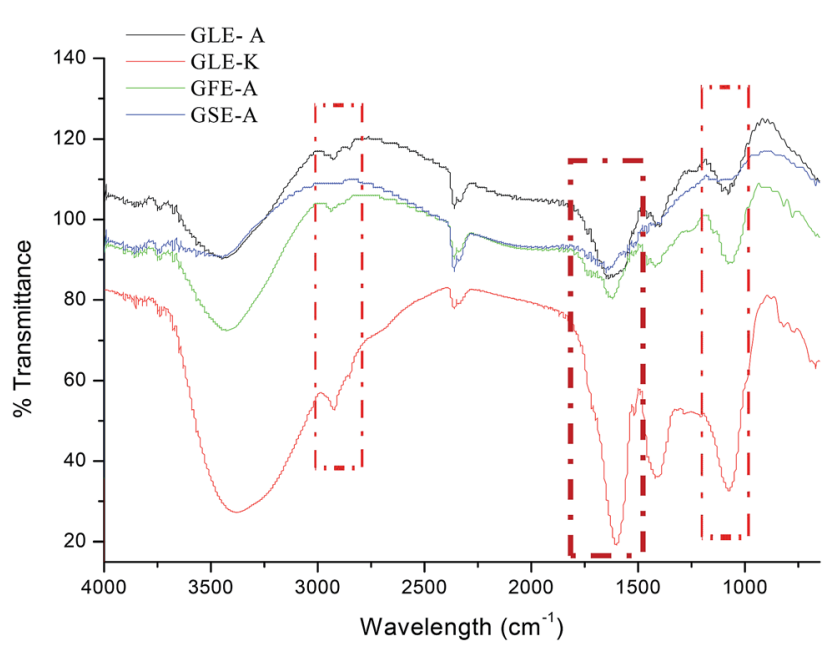

Fig. 6 FTIR spectra of GLE-A, GLE-K, GFE-A and GSE-A showing characteristic IR bands; highlighted regions are the regions of interests that correlate to the bioactive components in GEs. asymmetric $\mathrm{C}-\mathrm{H}$ and $2851.88 \mathrm{~cm}^{-1}$ signifies symmetric $\mathrm{C}-\mathrm{H}$. The absorption at $1743.72 \mathrm{~cm}^{-1}$ indicates the presence of acetogenin lactone, derived from $\mathrm{C}=\mathrm{O}$ on $\gamma$-butirolakton (ring consisting of five members). ${ }^{42}$ The broad peak at $3262.75 \mathrm{~cm}^{-1}$ $=\mathrm{OH}$ groups, $2936.15 \mathrm{~cm}^{-1}=\mathrm{CH}_{2}$ and $\mathrm{CH}$ alkenes groups, the peak at $1394.17 \mathrm{~cm}^{-1}=\mathrm{CH}_{3}$ alkane groups, and $1261 \mathrm{~cm}^{-1}=$ COC ester group. ${ }^{43}$ As observed in our FTIR results, GSE-A that showed no anti-astroglioma activity did not demonstrate any prominent acetogenin (lactone) band and other significant bands. In contrast, acetogenin bands were prominent in the spectra of GFE-A, GLE-A and GLE-K extracts.

The active isolates of graviola leaves also contain a class of compounds known as terpenoids. ${ }^{33,44}$ These can inhibit the cell cycle at the G2/M phase of mitosis, through inhibiting spindle formation. Additionally, terpenoids can trigger apoptosis through inhibition of the enzyme topoisomerase..$^{28}$ One group of terpenoids, namely, monoterpenoids, has anti-tumor activity. The mechanism of action of monoterpenoids is to suppress antitumor activity. ${ }^{30}$ Thus, from previous reports we can consolidate that graviola components modulate the network of cellular processes, such as the inhibition of signaling downstream pathways of the epidermal growth factor-receptor (EGF-R) and the downregulation of phosphatidylinositol-4,5-bisphosphate 3kinase (PI3-K/Akt), RAS, nuclear factor (NF)- $\mathrm{kB}$ and Janus kinase/ signal transducers and activators of transcription (JAK/STAT) ${ }^{45}$ They also modulate the inhibition of hypoxia-inducible factor (HIF)-1 $\alpha$, glucose transporter (GLUT)-1, and GLUT-4 (ref. 23) followed by pro-inflammatory cytokine expression (inflammation) and the generation of reactive oxygen species $^{43}$ via upregulation of enzyme systems like catalase (CAT), superoxide dismutase (SOD), and heme-oxygenase (HO-1) expression..$^{46,47}$

\section{Modulus operandi of acetogenins via MuD}

Annonaceous acetogenins (AAs), are reported to be highly potent inhibitors of mammalian mitochondria NADH- 
ubiquinone reductase (complex I).$^{48}$ To date, over 400 components of this compound have been discovered, all reputed to possess high cytotoxicity and anti-tumor activity, ${ }^{40}$ which was also further proven in the case of the astroglioma cells in this study. Mitochondria are the central relay station for apoptotic signal transduction. In response to apoptotic stimulus, permeabilized mitochondria release cytochrome $\mathrm{c}$ into the cytoplasm, where cytochrome $\mathrm{c}$ forms an apoptosome with Apaf-1 and caspase-9, which further triggers the caspase cascade. The key caspase in this cascade is caspase-3, which is cleaved and activated to transduce the apoptotic signal. ${ }^{49,50}$ Mitochondria can also release the apoptosis-inducing factor (AIF) to initiate caspase-independent cell death. ${ }^{51,52}$ The mitochondrial flavoprotein AIF is a caspase-independent cell-death-inducing factor. $^{53}$ At the time of apoptotic signaling, AIF gets released from the mitochondria when the mitochondrial membrane is permeabilized and is later translocated to the nucleus where it induces cell death/apoptosis by triggering chromatin condensation and large-scale DNA fragmentation. ${ }^{53-55}$ Han et al. ${ }^{56}$ confirmed that acetogenins trigger caspase-3-independent cell death, mediated by AIF through elaborate targeted experiments. Thus, acetogenins may trigger apoptosis via a MuD pathway interference.

\section{Conclusions}

The present study validates the impact of extracts from graviola leaves (from Korea and Africa), fruits and seeds against human astroglioma cells. The anti-cancer effects of various plant parts of graviola and within the same plant part (leaf) obtained from geographically different sources have been compared for their variations in anti-cancer activity. For the first time, we presented the correlation between graviola anti-cancer activity and MuD. This study exposed the underlying mechanism of the anticancer activity of graviola extracts from a MuD perspective. Further studies in this direction could help to shed more light on the exact mechanism behind this MuD perspective of graviola extracts.

\section{Conflicts of interest}

There are no conflicts to declare.

\section{Acknowledgements}

This paper was supported by Konkuk University in 2016 .

\section{References}

1 N. J. Abbott, L. Ronnback and E. Hansson, Nat. Rev. Neurosci., 2006, 7, 41-53.

2 G. S. Stoyanov, D. Dzhenkov, P. Ghenev, B. Iliev, Y. Enchev and A. B. Tonchev, Med. Oncol., 2018, 35, 27.

3 H. Kawasaki and K. Taira, Nucleic Acids Res., 2002, 30, 36093614.

4 M. R. Lee, J. N. Shin, A. R. Moon, S. Y. Park, G. Hong, M. J. Lee, C. W. Yun, D. W. Seol, S. Piya, J. Bae, J. W. Oh and T. H. Kim, Biochem. Biophys. Res. Commun., 2008, 370, 504-508.

5 J. H. Choi, J. B. Lim, D. D. Wickramanayake, Y. Wagley, J. Kim, H. C. Lee, H. G. Seo, T. H. Kim and J. W. Oh, Oncogenesis, 2016, 5, e221.

6 J. H. Choi, W. K. Min, J. Gopal, Y. M. Lee, M. Muthu, S. Chun and J. W. Oh, Int. J. Biol. Macromol., 2018, 117, 1147-1156.

7 S. Z. Moghadamtousi, M. Fadaeinasab, S. Nikzad, G. Mohan, H. M. Ali and H. A. Kadir, Int. J. Mol. Sci., 2015, 16, 1562515658.

8 S. Mishra, S. Ahmad, N. Kumar and B. K. Sharma, Global J. Pharm. Res., 2013, 2, 1613-1618.

9 A. K. Qazi, J. A. Siddiqui, R. Jahan, S. Chaudhary, L. A. Walker, Z. Sayed, D. T. Jones, S. K. Batra and M. A. Macha, Carcinogenesis, 2018, 39, 522-533.

10 E. B. Ribeiro de Souza, R. R. da Silva, S. Afonso and I. S. Scarminio, J. Sep. Sci., 2009, 32, 4176-4185.

11 S. O. Adewole and E. A. Caxton-Martins, Afr. J. Biomed. Res., 2006, 9, 173-187.

12 L. Taylor, Technical Data Report for Graviola, Annona muricata, Sage Press, 2002, vol. 10, pp. 1-6.

13 K. W. Pomper, J. D. Lowe, S. B. Crabtree and W. Keller, J. Agric. Food Chem., 2009, 57, 8339-8343.

14 S. C. Chun, X. M. Shang, V. Anthonydhason, H. Jung, S. T. Belachew, J. Gopal and D. Paul, Appl. Sci., 2018, 8, 232.

15 C. H. Ryu, W. S. Yoon, K. Y. Park, S. M. Kim, J. Y. Lim, J. S. Woo, C. H. Jeong, Y. Hou and S. S. Jeun, J. Biomed. Biotechnol., 2012, 2012, 987495.

16 S. Elmore, Toxicol. Pathol., 2007, 35, 495-516.

17 P. Ioannis, S. Anastasis and Y. Andreas, Am. J. Cancer Prev., 2015, 3, 128-131.

18 C. A. Pieme, S. G. Kumar, M. S. Dongmo, B. M. Moukette, F. F. Boyoum, J. Y. Ngogang and A. K. Saxena, $B M C$ Complementary Altern. Med., 2014, 14, 516.

19 M. Greenwell and P. K. Rahman, Int. J. Pharma Sci. Res., 2015, 6, 4103-4112.

20 L. Zeng, F.-E. Wu, Z.-M. Gu and J. L. McLaughlin, Tetrahedron Lett., 1995, 36, 5291-5294.

21 G. S. Kim, L. Zeng, F. Alali, L. L. Rogers, F. E. Wu, J. L. McLaughlin and S. Sastrodihardjo, J. Nat. Prod., 1998, 61, 432-436.

22 A. U. Ezirim, V. I. Okochi, A. B. James, O. A. Adebeshi, S. Ogunnowo and O. B. Odeghe, Glob. J. Res. Med. Plants Indig. Med., 2013, 2, 142-151.

23 M. P. Torres, S. Rachagani, V. Purohit, P. Pandey, S. Joshi, E. D. Moore, S. L. Johansson, P. K. Singh, A. K. Ganti and S. K. Batra, Cancer Lett., 2012, 323, 29-40.

24 S. Zorofchian Moghadamtousi, E. Rouhollahi, H. Karimian, M. Fadaeinasab, M. Firoozinia, M. Ameen Abdulla and H. Abdul Kadir, PLoS One, 2015, 10, e0122288.

25 S. Sun, J. Liu, H. Kadouh, X. Sun and K. Zhou, Bioorg. Med. Chem. Lett., 2014, 24, 2773-2776.

26 L. Zeng, F. E. Wu, N. H. Oberlies, J. L. McLaughlin and S. Sastrodihadjo, J. Nat. Prod., 1996, 59, 1035-1042.

27 L. Valencia, D. L. Munoz, S. M. Robledo, F. Echeverri, G. J. Arango, I. D. Velez and O. Triana, BIOmedica, 2011, 31, 552-559. 
28 L. Zeng, F. E. Wu and J. L. Mclaughlin, Bioorg. Med. Chem. Lett., 1995, 5, 1865-1868.

29 V. Kuete, J. K. Dzotam, I. K. Voukeng, A. G. Fankam and T. Efferth, SpringerPlus, 2016, 5, 1666.

30 S. H. Myint, D. Cortes, A. Laurens, R. Hocquemiller, M. Lebȩuf, A. Cavé, J. Cotteb and A.-M. Quérob, Phytochemistry, 1991, 30, 3335-3338.

31 H. Menan, J. T. Banzouzi, A. Hocquette, Y. Pelissier, Y. Blache, M. Kone, M. Mallie, L. A. Assi and A. Valentin, J. Ethnopharmacol., 2006, 105, 131-136.

32 O. P. Astirin, A. N. Artanti, M. S. Fitria, E. A. Perwitasari and A. Prayitno, J. Cancer Ther., 2013, 4, 1244-1250.

33 H. L. Ge, D.-W. Zhang, L. Li, D. Xie, J.-H. Zou, Y.-K. Si and J. Dai, Chem. Pharm. Bull., 2011, 59, 1541-1544.

34 I. Rady, M. B. Bloch, R. C. N. Chamcheu, S. B. Mbeumi, M. R. Anwar, H. Mohamed, A. S. Babatunde, J. R. Kuiate, F. K. Noubissi, K. A. El Sayed, G. K. Whitfield and J. C. Chamcheu, Oxid. Med. Cell. Longevity, 2018, 1826170.

35 C. C. Liaw, J. R. Liou, T. Y. Wu, F. R. Chang and Y. C. Wu, Prog. Chem. Org. Nat. Prod., 2016, 101, 113-230.

36 J. L. McLaughlin, J. Nat. Prod., 2008, 71, 1311-1321.

37 G. Deep, R. Kumar, A. K. Jain, D. Dhar, G. K. Panigrahi, A. Hussain, C. Agarwal, T. El-Elimat, V. P. Sica, N. H. Oberlies and R. Agarwal, Sci. Rep., 2016, 6, 23135.

38 A. Prayitno, A. N. Artanti, V. S. Dewangga, I. Abdullah, M. Hartati, M. S. Fitria, A. Elmanda and O. P. Astirin, Immunome Res., 2016, 12, 120.

39 H. Lusiana, T. T. Irawadi and I. H. Suparto, IPB (Bogor Agricultural University), Skripsi diterbitkan, 2009.

40 F. Q. Alali, X. X. Liu and J. L. McLaughlin, J. Nat. Prod., 1999, 62, 504-540.

41 P. Y. Pradana, S. Suratmo and R. Retnowati, Jurnal Ilmu Kimia Universitas Brawijaya, 2015, 1, 798-804.

42 R. M. Silverstein, F. X. Webster and D. J. Kiemle, Spectrometric Identification of Organic Compounds, John Wiley \& Sons, 7th edn, 2015.
43 N. N. N. N. M. Daud, H. Ya'akob and M. N. M. Rosdi, Integr. Cancer Sci. Ther., 2016, 3, 543-551.

44 F. E. Wu, Z. M. Gu, L. Zeng, G. X. Zhao, Y. Zhang, J. L. McLaughlin and S. Sastrodihardjo, J. Nat. Prod., 1995, 58, 830-836.

45 S. Z. Moghadamtousi, H. A. Kadir, M. Paydar, E. Rouhollahi and H. Karimian, BMC Complementary Altern. Med., 2014, 14, 299.

46 V. C. George, D. R. Kumar, V. Rajkumar, P. K. Suresh and R. A. Kumar, Asian Pac. J. Cancer Prev., 2012, 13, 699-704.

47 V. C. George, D. R. Kumar, P. K. Suresh and R. A. Kumar, J. Food Sci. Technol., 2015, 52, 2328-2335.

48 M. Degli Esposti, A. Ghelli, M. Ratta, D. Cortes and E. Estornell, Biochem. J., 1994, 301(1), 161-167.

49 J. Yuan, M. Lipinski and A. Degterev, Neuron, 2003, 40, 401413.

50 N. N. Danial and S. J. Korsmeyer, Cell, 2004, 116, 205-219.

51 S. P. Cregan, V. L. Dawson and R. S. Slack, Oncogene, 2004, 23, 2785-2796.

52 S. J. Hong, T. M. Dawson and V. L. Dawson, Trends Pharmacol. Sci., 2004, 25, 259-264.

53 S. A. Susin, H. K. Lorenzo, N. Zamzami, I. Marzo, B. E. Snow, G. M. Brothers, J. Mangion, E. Jacotot, P. Costantini, M. Loeffler, N. Larochette, D. R. Goodlett, R. Aebersold, D. P. Siderovski, J. M. Penninger and G. Kroemer, Nature, 1999, 397, 441-446.

54 N. Joza, S. A. Susin, E. Daugas, W. L. Stanford, S. K. Cho, C. Y. Li, T. Sasaki, A. J. Elia, H. Y. Cheng, L. Ravagnan, K. F. Ferri, N. Zamzami, A. Wakeham, R. Hakem, H. Yoshida, Y. Y. Kong, T. W. Mak, J. C. Zuniga-Pflucker, G. Kroemer and J. M. Penninger, Nature, 2001, 410, 549-554.

55 E. Daugas, S. A. Susin, N. Zamzami, K. F. Ferri, T. Irinopoulou, N. Larochette, M. C. Prevost, B. Leber, D. Andrews, J. Penninger and G. Kroemer, FASEB J., 2000, 14, 729-739.

56 B. Han, T. D. Wang, S. M. Shen, Y. Yu, C. Mao, Z. J. Yao and L. S. Wang, BMC Cancer, 2015, 15, 139. 